\title{
KANT E RAWLS: UMA ANÁLISE DOS PRESSUPOSTOS MORAIS DO LIBERALISMO POLÍTICO
}

\author{
Kant and Rawls: an analysis of the moral \\ assumptions of political liberalism \\ Kant y Rawls: un análisis de los presupuestos \\ morales del liberalismo político
}

Douglas João Orben'

Faculdade Palotina, Santa Maria, RS, Brasil.

\section{Resumo}

À luz das reformulações conceituais acerca dos pressupostos filosóficos aceitos por Rawls no desenvolvimento de sua teoria da justiça, o presente artigo objetiva questionar a ideia de autossustentabilidade do âmbito político, como exposto em Political Liberalism (1993), evidenciando alguns pressupostos morais não explicitados pelo autor. A partir de um acordo semântico proposto por Rainer Forst, o qual diferencia os âmbitos de aplicação do ético, do político e do moral, pretende-se demostrar que há uma fundamentação moral no liberalismo político, a qual, todavia, não deve ser entendida no sentido ético. Propõe-se que esse pressuposto moral se encontra na razão prática kantiana, pois é daí que Rawls parte para estruturar e fundamentar a sua concepção de justiça. Com isso, os princípios do liberalismo político rawlsiano, para que possam ser efetivos quando aplicados à estrutura básica da sociedade, devem ser analisados mediante os elementos morais da razão prática kantiana.

Palavras-chave: Ética. Moral. Política. Razão prática.

\footnotetext{
Doutor em Filosofia pela Pontifícia Universidade Católica do Rio Grande do Sul (PUCRS) e professor do curso de Filosofia da Faculdade Palotina (FAPAS), Santa Maria, RS, Brasil. ORCID: http://orcid.org/oooo-0002-5245-7630. E-mail: douglasorben@hotmail.com
} 


\begin{abstract}
In the light of conceptual reformulations about the philosophical assumptions accepted by Rawls in the development of his theory of justice, the present article aims to question the idea of freestanding of the political scope, as discussed in Political Liberalism (1993), evidencing some moral assumptions not explained by the author. From a semantic agreement proposed by Rainer Forst, which differentiates the scopes of application of ethics, politics, and morals, the attempt of this discussion is to demonstrate that there is a moral foundation in political liberalism, which, however, should not be understood in an ethical sense. The proposition is that this moral presupposition lies in Kantian practical reason, for it is from this that Rawls starts to structure and ground his conception of justice. Hence, the principles of Rawlsian political liberalism, in order to be effective when applied to the basic structure of society, must be analyzed through the moral elements of Kantian practical reason.
\end{abstract}

Keywords: Ethics. Morals. Politics. Practical reason.

\title{
Resumen
}

A la luz de las reformulaciones conceptuales en las hipótesis filosóficas aceptadas por Rawls en el desarrollo de su teoría de la justicia, este artículo pretende cuestionar la idea de la sostenibilidad de la esfera política, como expuesto en política Political Liberalism (1993), evidenciando algunas suposiciones morales no explicadas por el autor. Partiendo de acuerdo semántico propuesto por Rainer Forst, que distingue los campos de aplicación de la ética, de lo moral y de lo político, se pretende demostrar que hay un razonamiento moral en liberalismo político, que, sin embargo, no debe entenderse en el sentido ético. Se propone que esta suposición moral esté en la razón práctica kantiana, pues es ahí donde Rawls deja para estructurar y fundamentar su concepción de la justicia. Con eso, los principios del liberalismo político rawlsiano, para que pueden ser eficaces cuando aplicados a la estructura básica de la sociedad, deben ser analizados a través de los elementos morales de la razón práctica kantiana.

Palabras clave: Ética. Moral. Política. Razón práctica.

\section{Introdução}

A proposta filosófica de John Rawls destaca-se no cenário moral e político com a publicação da obra $A$ Theory of Justice (1971). Essa se estabelece como uma das mais importantes obras de filosofia política do 
século XX, tanto por seu modo inovador de tratar as principais questões relacionadas ao seu domínio de discussão, bem como pela retomada e pela ressignificação de alguns conceitos e teorias tradicionais da filosofia. O primeiro aspecto figura na proposta de uma concepção de justiça como equidade (justice as fairness), enquanto o segundo remete (sobretudo) à apropriação crítica da moralidade kantiana. O projeto rawlsiano é edificado mediante um intenso diálogo e contraposição ao utilitarismo e ao intuicionismo moral, pelo que o autor propõe um construtivismo nos moldes da filosofia prática kantiana. Como asseverado inicialmente em A Theory of Justice, tal empreendimento remonta à teoria tradicional do contrato social como representada por Locke, Rousseau e Kant. Além do mais, o seu perfil construtivista faz com que Rawls reconheça que essa teoria "é altamente kantiana em sua natureza" (RAWLS, 1997, p. XXII).

A despeito do caráter evolutivo que caracteriza a produção filosófica rawlsiana, um work in progress, em $A$ Theory of Justice boa parte dos elementos constitutivos da justiça como equidade já estão identificados. Muito embora inspirada e de natureza kantiana, Rawls ressalta que a sua teoria está voltada para uma concepção social, para a estrutura básica da sociedade (the basic structure of society), não se comprometendo assim com a concepção metafísica/transcendental de Kant. Neste sentido, o propósito é estabelecer e justificar os critérios pelos quais "as principais instituições sociais distribuem direitos e deveres fundamentais e determinam a divisão de vantagens decorrentes da cooperação social" (RAWLS, 1997, p. 11). Esse empreendimento é levado a cabo por meio de uma interpretação construtivista da moral kantiana, utilizando-se de um procedimentalismo puro que busca justificar publicamente os princípios normativos de uma sociedade justa.

Todavia, a obra de 1971 não deixa ainda evidente a diferenciação entre uma concepção moral, doutrina abrangente (comprehensive doctrine), e uma concepção política de justiça. Essa diferenciação começa a delimitar-se no decorrer da obra rawlsiana, na qual se pode visualizar um progressivo afastamento das concepções abrangentes inicialmente adotadas. Este é o processo de politização (Politisierung), como denominado por Kersting 
(KERSTING, 1996, p. 256), o qual é levado a cabo em Political Liberalism (1993)2, mas que tem o seu início nas John Dewey Lectures (1980). Nas preleções sobre Kantian Constructivism in Moral Theory, Rawls já acena no sentido de converter a teoria da justiça para uma concepção política, não vinculada a pressupostos éticos ou doutrinas abrangentes. No entanto, tal processo é levado a cabo principalmente em Political Liberalism (1993), obra esta em que o autor se contrapõe ao construtivismo moral como apresentado em $A$ Theory of Justice, pois uma concepção política de justiça seria necessária para atender às profundas divergências (éticas, filosóficas, religiosas), produzidas pelo pluralismo presente nas sociedades contemporâneas.

Contudo, mesmo pretendendo afastar-se de pressupostos morais (abrangentes), o projeto rawlsiano encontra-se profundamente comprometido com a interpretação kantiana que perpassa todas as suas obras, principalmente com a sua concepção de construtivismo moral (RAWLS, 2011, p. 107-120). Nesse enredo, apesar do processo de politização, as questões aqui levantadas são as seguintes: a concepção política de justiça sustenta-se sem pressupostos morais ou éticos? Há diferença semântica entre os conceitos de ética e moral? A teoria da justiça rawlsiana, mesmo quando exposta como uma concepção estritamente política, não estaria fundamentada em pressupostos morais kantianos?

\section{Uma demarcação entre os diferentes contextos de justiça}

O processo de politização da obra rawlsiana, iniciado nos anos de 1980, apresenta-se em sua completude em Political Liberalism (1993). Nesse

\footnotetext{
2 Rainer Forst, na obra Contexts of Justice, apresenta a seguinte análise sobre tal processo evolutivo da filosofia rawlsiana: "nos textos de Rawls escritos desde "Justiça como equidade: uma concepção política, não metafísica" (1985), podem ser estabelecidas importantes modificações adicionais em sua teoria, que levaram a uma reformulação no livro Political Liberalism, cujo título é um programa: Rawls ressalta mais fortemente a pretensão de uma fundamentação não metafísica da teoria e seu caráter "político" em um sentido epistemológico. A teoria se afasta mais fortemente das concepções éticas do bem e se concentra na tarefa prático-normativa de poder se afirmar em um "consenso sobreposto" (fundamentado "razoavelmente") de um estado eticamente pluralista" (FORST, 2010, p. 223).
} 
contexto, o construtivismo limita-se ao domínio de uma concepção política, adotando princípios públicos e intersubjetivamente reconhecidos. Sob o domínio de valores políticos ${ }^{3}$, seria possível se levar a cabo um consenso sobreposto, em um contexto social marcado pelo pluralismo de concepções e ideias. Com isso, as doutrinas abrangentes são excluídas do construtivismo político, não porque elas não sejam relevantes, mas sim porque dificilmente se chegaria a um acordo geral sobre alguma concepção abrangente que pudesse ser subscrita por todos os cidadãos. No procedimento de construção de princípios políticos, a autonomia racional (RAWLS, 2011, p.85-92) das partes na posição original (original position) (RAWLS, 2011, p. 78-85) modela, em condições equitativas de liberdade e igualdade, a autonomia plena (RAWLS, 2011, p. 92-97) dos cidadãos que habitam uma sociedade bem-ordenada (well-ordered society) (RAWLS, 2011, p. 41-48). Esse processo, aliás, ocorre mediante a aplicação dos princípios de justiça construídos na posição original à estrutura básica da sociedade. Ao viver em uma sociedade bem-ordenada, na qual as principais instituições expressam os valores políticos construídos mediante condições equitativas, a personalidade política dos cidadãos vai sendo constituída conforme os princípios públicos e reconhecidos pela razão prática de todos. Esses cidadãos estão submetidos a princípios políticos que eles próprios compreendem como construídos pelo uso da razão prática, e assim eles se reconhecem como politicamente autônomos, como autores das leis às quais estão submetidos. Deste modo, pois, é possível um consenso sobreposto (overlapping consensus) (RAWLS, 2011, p. 170-182), sobre estes valores políticos e públicos.

\footnotetext{
3 Segundo Freeman, o estabelecimento de um domínio autônomo do político é algo fundamental para compreender a questão levantada em Political Liberalism. Segundo o autor, "a ideia da independência da teoria moral desempenha um papel importante no liberalismo político de Rawls. Pois as ideias de "domínio do político" e de "concepção autônoma de justiça" supõem um domínio do raciocínio prático sobre "o político", o qual não é apenas independente da filosofia teórica - da metafísica, epistemologia, etc.- mas também é independente de todas as teorias morais abrangentes." Sob este domínio do político, Rawls consegue explicar a ideia de consenso sobreposto de doutrinas abrangentes razoáveis (FREEMAN, 2007, p. 315).
} 
No que tange à autonomia plena, esta é uma ideia que diz respeito à personalidade pública dos cidadãos. Pressupõe-se, aqui, uma concepção normativa de pessoa, pois se vincula a deveres e prerrogativas políticas dos cidadãos. "Assim, a autonomia plena é realizada pelos cidadãos quando agem de acordo com os princípios de justiça que especificam os termos equitativos de cooperação que aplicariam a si mesmos, quando equitativamente representados como pessoas livres e iguais" (RAWLS, 2011, p. 92). Os princípios políticos de justiça, construídos em condições hipotéticas pela autonomia artificial das partes racionais, modelam a autonomia plena de cidadãos reais, que habitam uma sociedade bem-ordenada. Do mesmo modo, mediante a capacidade reflexiva da razão prática, cada cidadão pode avaliar, revisar e construir princípios políticos ponderados. Todavia, a autonomia política dos cidadãos normatiza apenas as suas vidas públicas, i.e., enquanto pessoas de direitos e deveres políticos. Por pertencer à esfera do político, a autonomia plena não diz respeito ao âmbito ético da identidade pessoal. A identidade ética de cada pessoa pode ser livremente escolhida, revisada e modificada conforme as suas preferências, dentro dos limites do razoável (reasonable). Ela está relacionada às concepções de vida boa que cada pessoa julga ser a melhor ou mais racional (rational) para ser efetivada (RAWLS, 2011, p. 5764). Nesse âmbito, encontram-se os vínculos afetivos, costumes, hábitos, concepções religiosas e interesses associativos de um modo geral, os quais não dizem respeito à vida pública. Tem-se, aqui, uma ideia herdada de Kant (1984), segundo a qual esse âmbito da identidade pessoal está vinculado aos imperativos hipotéticos, como no caso dos conselhos de prudência que visão à satisfação da felicidade pessoal, o que é algo subjetivo, relativa às disposições empíricas de cada indivíduo. À luz desta ideia, Rawls assevera o seguinte: "a autonomia plena é atingida pelos cidadãos: é um valor político, não um valor ético. Com isso, quero dizer que ela se realiza na vida pública pela afirmação dos princípios políticos de justiça e pelo usufruto das proteções dos direitos e liberdades básicos". Consequentemente, "essa autonomia plena da vida política deve ser distinguida dos valores éticos da autonomia e da individualidade, que podem aplicar-se à vida como um todo, tanto social 
quanto individual" (RAWLS, 2011, p. 92-93). Como exemplos de concepções éticas abrangentes, as quais não estariam relacionadas à autonomia plena dos cidadãos políticos, Rawls cita os liberalismos abrangentes de Kant ${ }^{4} \mathrm{e}$ Mill.

Nesse contexto, é interessante perceber que no supracitado trecho do $\S 6$ da obra de 1993 (Political Liberalism) o autor estadunidense afirma que a concepção abrangente kantiana diz respeito ao âmbito ético, pois se aplica à vida como um todo. Ora, essa ideia já havia sido apresentada em Kantian Constructivism in Moral Theory (1980), quando o construtivismo político se separa do construtivismo kantiano. O inusitado é que, desde então, Rawls, por várias vezes, denominou a posição filosófica de Kant como uma concepção moral abrangente, e não ética. $O$ que isso revela é que Rawls não faz uma distinção no uso dos conceitos de "ético" e "moral" ou até mesmo os confunde, pois ora se refere a doutrinas morais abrangentes, ora fala em concepções éticas abrangentes. O construtivismo kantiano é qualificado tanto como "moral abrangente", bem como relacionado ao âmbito dos valores éticos. Mas o que se deseja, no fundo, é ressaltar que o liberalismo adota uma concepção política de justiça, separando-se do âmbito das doutrinas abrangentes. Aliás, em vários momentos Rawls afirma que o construtivismo político é também moral ou que a sua concepção de liberalismo político tem pressupostos morais, os quais têm o sentido público do político (RAWLS, 2011, p. 12-18). Perante esse cenário marcado por falta de clareza, Rainer Forst alerta que a linguagem utilizada por Rawls pode tornar-se enganadora (FORST, 2010, p. 57). Ora, como compreender os significados relacionados aos diferentes usos dos termos "ética", "moral" e "política"? Qual a diferença entre uma concepção moral e uma doutrina ética? Há uma fundamentação ética ou moral do político?

\footnotetext{
4 Para Freeman, enquanto a autonomia doutrinal de Rawls é uma concepção política, "a autonomia constitutiva, por outro lado, é o tipo de autonomia do construtivismo kantiano [...]. Ela é uma tese epistemológica sobre as origens filosóficas da moralidade: diz que os princípios morais são constituídos a partir da atividade da razão prática, e que estes não têm suas origens em uma ordem moral independente (como a vontade de Deus)" (FREEMAN, 2007, p. 354-355). A diferença, portanto, está no fato de que a autonomia kantiana é mais profunda, por assim dizer, pois ela exige uma postura que implica diretamente na identidade pessoal do sujeito.
} 
Uma resposta às supracitadas questões pode ser encontrada na obra Contextos da Justiça, de R. Forst, mais precisamente na primeira parte $\mathrm{da}^{5}$ obra, onde o autor apresenta uma análise da contenda entre comunitaristas e liberais. Ao analisar a crítica de Sandel à identidade artificial dos cidadãos no liberalismo rawlsiano, os quais seriam desengajados de uma comunidade constitutiva, Forst afirma que se faz necessário distinguir diferentes formas de comunidades nas quais as pessoas possuem diferentes identidades, com compromissos, deveres e direitos que podem variar conforme o contexto. Há que se estabelecer um acordo semântico ${ }^{6}$ sobre quatro conceitos de comunidades, cada qual com seu contexto de justiça, tendo um correspondente conceito de pessoa: o ético, o jurídico, o político e o moral. À luz deste esclarecimento semântico, é possível elucidar a citada ambiguidade dos conceitos utilizados por Rawls.

Nesse sentido, o contex to ético diz respeito à comunidade civil e engloba uma pluralidade de costumes, hábitos culturais, associações, doutrinas religiosas e concepções de bem. Nesse âmbito, a identidade pessoal é constituída pelas relações de afeto, lealdade, amizade, interesse e afinidade, as quais são estabelecidas conforme as diferentes concepções de bem escolhidas por cada pessoa. Essas concepções são subjetivamente articuladas visando à satisfação de interesses e preferências pessoais, como no caso da busca por uma vida feliz e subjetivamente significativa. O contexto jurídico é aquele em que o sujeito é tratado como pessoa de direito, ele "pode também ser caracterizado como 'identidade jurídica', pois aqui a pessoa é considerada como sujeito de direito, como pessoa com um status legal" (FORST, 2010, p. 38). Esse é o âmbito em que as leis do sistema judiciário determinam a identidade legal, com direitos e deveres, relacionados às pessoas do direito. O contexto político, por sua vez, está relacionado à identidade pública das pessoas, enquanto cidadãos políticos

\footnotetext{
5 Esta discussão é apresentada, sobretudo, no primeiro e segundo capítulo da obra. Sob os títulos respectivamente: $A$ constituição do Eu e A neutralidade ética do direito. Cf. FORST, R. Contextos da Justiça. São Paulo: Boitempo Editorial, 2010.
}

6 Aqui, seguimos de perto a leitura feita pelo professor Thadeu Weber sobre esta questão, apresentada no artigo: Fundamentação Moral do Liberalismo Político. Cf. WEBER Thadeu. Fundamentação moral do liberalismo político de Rawls. Ethic@, Florianópolis, v. 15, n. 3, p. 398-417, dez. 2016. 
que têm autonomia para serem autores das normas do direito e dos princípios da política. Por fim, a esfera moral vincula-se aos princípios universalíssimos que determinam os direitos fundamentais de toda a humanidade. Aqui, todos os seres humanos são considerados como possuidores de direitos morais universais e invioláveis. Independentemente das condições sociais, culturais, políticas ou concepções de bem que alguém possa ter, enquanto pessoa moral, todos têm direitos que são inalienáveis. Esses direitos fundamentais estão no âmbito universal da moralidade e são objetivamente reconhecidos.

Considerando tais diferenças relativas aos contextos de justiça, Forst (2010) ressalta que há uma relação harmônica entre as múltiplas comunidades existentes, de modo que uma mesma pessoa pode fazer parte de todas, ao mesmo tempo. Enquanto pertencendo a uma comunidade ética, a pessoa não perde o seu status jurídico, nem a sua autonomia política e muito menos os seus direitos morais fundamentais. Todavia, cada contexto impõe ao sujeito obrigações e direitos diferentes, mas não contraditórios. Os princípios jurídicos e políticos, por exemplo, não podem estar vinculados ou dependentes de concepções éticas de bem, entretanto aqueles constituem uma "capa protetora" para estes. Segundo Forst, "a identidade da pessoa de direito coloca, por assim dizer, uma capa abstrata externa para a pessoa ética; protege a identidade particular de uma pessoa e, ao mesmo tempo, limita-a segundo princípios da justiça morais e universais" (FORST, 2010, p. 38. Grifos do autor). Com efeito, o contexto jurídico "assegura ao eu ético constituído comunitariamente um espaço de liberdade para poder desenvolver sua identidade e assegurar a possibilidade formal para examinar criticamente e revisar essa identidade" (FORST, 2010, p. 38). Uma mudança, mesmo que radical e profunda, na identidade ética de uma pessoa não altera o seu status jurídico ou político.? Sendo complementares,

\footnotetext{
7 Isso, por exemplo, é o que ocorre no caso de uma conversão religiosa, a qual é assegurada com um direito jurídico e não altera a identidade política da pessoa. Assim, "quando os cidadãos se convertem a uma outra religião, por exemplo, ou não professam mais uma fé religiosa estabelecida, não deixam de ser, em questões de justiça política, as mesmas pessoas de antes. Não há perda alguma do que podemos chamar de sua identidade pública ou institucional, nem de sua identidade em termos de lei fundamental" (RAWLS, 2011, p. 35).
} 
essas dimensões não devem ser reduzidas uma a outra: "relações jurídicas não substituem relações éticas, bem como não são substituídas por elas" (FORST, 2010, p. 40). Da mesma maneira, o domínio do político faz parte da esfera moral, pois esse estabelece princípios universais os quais são integrados pelo político. Os valores políticos, portanto, não podem contrariar os princípios morais, do mesmo modo que as concepções éticas de bem não podem violar leis jurídicas ou políticas. Por evidente, todas as diversas doutrinas éticas devem respeitar os princípios morais universalíssimos. Assim compreende-se a limitação rawlsiana do liberalismo político a um contexto plural de doutrinas abrangentes razoáveis, as quais devem respeitar os princípios morais da justiça. As concepções éticas que violam princípios da esfera moral, portanto, são tratadas como não razoáveis.

No tocante à justificação de cada contexto da justiça, há diferentes formas de validação e aplicação das normas relativas a cada comunidade: princípios morais devem ser justificados universalmente e aplicam-se a todos os seres humanos; já os valores políticos e jurídicos são validados pela publicidade e pelo conceito de justiça, estendendo-se a uma determinada sociedade política; e, por fim, as concepções éticas de bem são justificadas individualmente, pelas preferências e interesses de cada um, não necessitam de justificação pública ou universal, pelo que só são válidas para aqueles que deliberadamente desejam fazer parte delas. Sobre essa questão, é interessante atentar ao seguinte comentário feito por Forst:

As normas e princípios válidos universalmente, diferentemente dos valores éticos e concepções de bem, devem ser justificados universalmente, sem recorrer a concepções particulares de bem. Diferentemente dos valores éticos, normas jurídicas e normas morais têm a pretensão de contar com uma validade universal fundamentada "para todos", não importa quais concepções éticas as pessoas adotem. Normas jurídicas pedem a observância de todos os parceiros do direito enquanto membros de uma determinada comunidade jurídica e são 
resultado de um processo de legislação realizado no interior de uma comunidade política, ao passo que as normas morais pretendem ter validade universal, isto é, vinculam todos os seres humanos enquanto membros da comunidade dos seres humanos [...]. Em contraposição, os valores éticos têm uma outra pretensão de validade: são válidos apenas para indivíduos que se podem identificar com esses valores, isto é, que podem afirmá-los como parte de suas identidades do ponto de vista de sua história de vida (FORST, 2010, p. 41. Grifos do autor).

Considerando os vários contextos da justiça, percebe-se que o âmbito político faz parte do moral, de modo que há um fundamento moral nos princípios políticos. Todavia, não se pode admitir um embasamento ético ao âmbito político, pois a justificação das concepções éticas não atende às exigências de publicidade e reciprocidade do político (RAWLS, 2011, p. 251-268). Desse modo, embora seja necessário separar o âmbito político do ético, é possível defender uma fundamentação moral do político. É, aliás, nesse sentido que Forst esclarece as supracitadas imprecisões no uso dos conceitos de "ético", "político" e "moral" na obra de Rawls. Assim, quando Rawls afirma que o âmbito político não pressupõe nenhuma "doutrina moral abrangente", "o sentido do termo "moral", do qual Rawls se afasta, é o sentido ético de uma concepção que está fundamentada em valores últimos e que se referem à vida boa" (FORST, 2010, p. 57). O "moral”, aqui, denota um valor ético, pois Rawls deseja ressaltar a independência da posição política com relação a toda e qualquer concepção ética de bem, e o faz justamente porque não é possível justificar publicamente tais concepções. O mesmo ocorre quando Rawls trata da concepção política de pessoa, no $\S 5$ da primeira conferência de Political Liberalism: ele a distingue da identidade ética, a qual é caracterizada pelos fins e compromissos mais profundos dos cidadãos, mas a denomina de "identidade moral ou não institucional". Mais adiante, Rawls reforça esse equívoco ao asseverar que esses compromissos "especificam a identidade moral e 
dão forma ao estilo de vida de uma pessoa, àquilo que a própria pessoa julga estar fazendo e tentando realizar no mundo social" (RAWLS, 2011, p. 36). Ora, parece evidente que o uso do conceito de "identidade moral", aqui, realmente denota a ideia de "identidade ética". Isso se torna ainda mais evidente quando o autor estadunidense afirma que esta concepção de identidade pessoal pode mudar, e que "quando essas mudanças são abruptas, podemos dizer que não somos mais a mesma pessoa". Como exemplo, é citado um caso de conversão religiosa que implica em mudanças profundas na identidade ética - mais uma vez, Rawls fala em identidade moral (RAWLS, 2011, p. 37) da pessoa: "na estrada de Damasco, Saulo de Tarso se transforma em Paulo, o Apóstolo" (RAWLS, 2011, p. 37) e isso faz com que ele modifique radicalmente a sua forma de vida. Tendo em vista esse caso, parece evidente que Rawls está se referindo à identidade ética e às diversas concepções de bem que podem ser livremente escolhidas e modificadas, conforme as preferências individuais. Esse processo de constituição da identidade pessoal está relacionado ao domínio ético das concepções abrangentes de bem, e não aos princípios universais da esfera moral. Não por acaso, essas concepções éticas podem ser livremente modificadas, sem que isso altere a identidade política da pessoa.

Certamente, o que Rawls deseja ressaltar é que tais mudanças na identidade ética de uma pessoa, por mais radicais e profundas que possam ser, não afetam a sua identidade política, pois o âmbito político justifica-se de modo independente de toda e qualquer concepção ética abrangente. Com efeito, uma conversão religiosa ou mesmo qualquer ressignificação na identidade ética não implica em nenhuma mudança na identidade pública de qualquer cidadão. É, pois, nesse sentido que a autonomia política deve ser entendida: como totalmente independente das concepções éticas de bem, mas vinculada a deveres e prerrogativas jurídicas e públicas. A despeito da falta de clareza no uso dos citados conceitos na obra rawlsiana, o acordo semântico proposto por Forst deixa claro o seguinte: a independência do âmbito político diz respeito às concepções éticas de bem, as quais não se enquadram nos critérios de publicidade exigidos na justificação do constru- 
tivismo político. Se, de fato, o que Rawls deseja é afirmar a independência do político com relação ao ético, então outra questão se impõe: haveria uma fundamentação moral do político? Ou seja, o liberalismo político pode estabelecer-se de modo independente do âmbito moral, o qual apresenta princípios universalmente válidos? Ou será que o político é parte do moral e, assim, os princípios morais seriam pressupostos imprescindíveis ao domínio do político. Considerando as pretensões do liberalismo rawlsiano, parece evidente que o âmbito político não pode assimilar concepções éticas de bem. Mas, o que dizer sobre os valores morais universalíssimos?

Inicialmente, para responder essas questões, torna-se importante ressaltar que a independência da concepção política de justiça é uma premissa fundamental para se levar a cabo um acordo estável, em uma sociedade marcada pelo pluralismo razoável de doutrinas éticas abrangentes. Por outro lado, considerando o acordo semântico proposto por Forst, é possível pensar que uma vinculação da concepção política de justiça a princípios morais não comprometeria a ideia de um consenso sobreposto de doutrinas éticas abrangentes. Isso porque a esfera moral atende aos mesmos critérios de justificação do domínio político, pois a universalidade dos princípios morais acolhe os requisitos de reciprocidade e publicidade exigidos pelo político. Pode-se dizer, inclusive, que o princípio moral vai além do político e assegura uma justificação universal, válida para todos os seres humanos. Diferentemente das concepções éticas, sobre as quais dificilmente se chegaria a um acordo político, pois elas se estruturam a partir de interesses privados e subjetivos, os princípios morais são compartilhados por todos. Este parece ser o sentido atribuído por Rawls ao termo "moral", quando ele se refere às "faculdades morais dos cidadãos" ou ainda quando afirma que uma concepção política é também moral. Do mesmo modo, as ideias de igualdade e liberdade, na medida em que exigem qualidades mínimas dos cidadãos, denotam uma concepção moral pressuposta. Essas são exigências básicas para que o construtivismo político rawlsiano possa ser edificado, pois nem tudo pode ser construído (RAWLS, 2011, p. 20-27). 


\section{A doutrina moral kantiana como pressuposto necessário ao liberalismo político}

$\mathrm{Na}$ vastíssima esfera de discussões engendradas pela filosofia rawlsiana, há várias objeções ${ }^{8}$ à ideia de autossustentabilidade (freestanding) dos princípios de justiça, como apresentada em Political Liberalism. Não são poucos os críticos que contestam a independência da concepção política de justiça e, geralmente, of fazem assinalando para pressupostos morais ou éticos não devidamente considerados na obra de 1993. Além destas objeções que se concentram sobre fundamentos morais, há outras críticas que incidem sobre a concepção-modelo de sociedade bem-ordenada, como redefinida e limitada nos últimos escritos acerca do assunto. Estabelecida como uma concepção que integra a posição original, essa ideia limita a aplicabilidade dos princípios de justiça conforme os padrões políticos das sociedades democráticas constitucionais modernas. Nesse caso, a justiça como equidade partiria de certas ideias fundamentais, as quais estariam implícitas na cultura política das sociedades democráticas, de modo que a teoria rawlsiana só aplicar-se-ia a sociedades com este perfil político. Sociedades que não reconhecem a liberdade e a igualdade como valores políticos fundamentais, portanto, não seriam razoáveis, nem aceitariam os princípios do liberalismo rawlsiano.

Perante essa limitação, segundo as principais objeções, o construtivismo político estaria dependente de uma determinada concepção liberal de sociedade, a qual dificilmente deixaria de manifestar um ponto de vista ético-cultural, como pressuposto orientador de tal sociedade. Mesmo Rawls ressaltando que o construtivismo político não se vincula a qualquer doutrina ética abrangente, pode-se supor que a concepção-modelo de sociedade bem-ordenada pressupõe algo como uma postura liberal, característica das democracias constitucionais modernas. Para esse viés crítico,

\footnotetext{
8 Nesse sentido, por exemplo, influenciado pelas críticas de Ronald Dworkin à teoria da justiça rawlsiana, Charles Larmore afirma que o liberalismo político perde de vista as suposições morais que inspiram e fundamentam o seu próprio projeto (Cf. LARMORE, 2008, p. 139). Além do mais, pode-se mencionar, entre outros, os seguintes casos: Estlund (1998); Hampton (1996); Wenar (1995) e Mahoney (2007).
} 
na medida em que Rawls limita a aplicação de sua teoria a essa ideia de sociedade, torna-se evidente que ele está pressupondo uma concepção ética de bem, presente nas culturas democráticas modernas, sem a qual o liberalismo político não teria efetividade. Contudo, o filósofo estadunidense vai objetar essas críticas afirmando que tal ideia de sociedade não envolve elementos extraídos de concepções éticas ou mesmo de visões abrangentes sobre o bem, as quais são parte da cultura social (RAWLS, 2011, p. 12-18). A concepção-modelo de sociedade bem-ordenada extrai os seus princípios da cultura política, a qual é constituída historicamente e se expressa em instituições e valores públicos. “Essa cultura pública compreende as instituições políticas de um regime constitucional e as tradições públicas de sua interpretação (inclusive as do judiciário), bem como os textos e documentos históricos que são de conhecimento geral" (RAWLS, 2011, p. 16). Mesmo integrando valores sociais, o construtivismo político não estaria apelando a concepções éticas de bem, pois ele se fundamenta em valores políticos e publicamente reconhecidos por todos os cidadãos.

Contudo, à luz de todas estas discussões acerca de possíveis pressupostos à ideia de autossustentabilidade do liberalismo político, parece plausível defender que há uma fundamentação moral para o âmbito político, embora seja necessário distingui-la do domínio ético. Segundo o acordo semântico estabelecido a partir da leitura proposta por Forst, torna-se possível pressupor um fundamento moral ao político, porém não ético. Como é evidente, o que o liberalismo político pretende evitar é estar vinculado a concepções éticas de bem, pois essas têm caráter privado e subjetivo. Por outro lado, o âmbito moral não teria essas características, já que se trata de valores universais e reconhecidos pela razão prática. Aliás, princípios morais universalíssimos não comprometeriam a estabilidade do âmbito político, nem a efetivação de um possível consenso sobreposto de concepções éticas razoáveis. Isso porque, sendo universais, esses princípios morais são publicamente reconhecidos pela razão prática de todos os cidadãos razoáveis. A estabilidade dos princípios de justiça, bem como a possibilidade de se alcançar um consenso sobreposto, não 
se dá pelo simples status político da teoria, mas sim pela objetividade que permite o reconhecimento público dos princípios escolhidos. Essa é, pois, uma característica dos valores universalíssimos da esfera moral. Portanto, muito embora Rawls não tenha pressuposto qualquer princípio moral ao seu liberalismo, apostando assim na ideia de um construtivismo estruturado mediante um procedimentalismo puro, é plausível e relevante elucidar esses possíveis pressupostos presentes em seu projeto.

Neste cenário de objeções à ideia de autossustentabilidade do âmbito político, todas as discussões remetem a uma questão central que carece de elucidação, a saber: esse possível fundamento moral, pressuposto ao liberalismo político, não estaria na razão prática kantiana? Considerando que Rawls assumidamente fundamenta-se no construtivismo moral kantiano (RAWLS, 2000 p. 43-140), não estaria aí, portanto, o assinalado pressuposto moral do liberalismo político? Como mencionado anteriormente, a partir dos anos 1980, com a publicação das John Dewey Lectures, o filósofo estadunidense afasta-se da concepção moral de Kant, bem como de toda e qualquer concepção filosóficas abrangente. Esse processo é levado a cabo com a publicação de Political Liberalism, em 1993, no qual o autor apresenta a ideia de autossustentabilidade do âmbito político e rechaça qualquer pressuposto ético ou moral abrangente. Aqui, aliás, Rawls ressalta que a concepção moral kantiana não desempenha qualquer função na estabilidade do âmbito político, pois ela expressa uma doutrina filosófica abrangente, fundamentada no idealismo transcendental. No entanto, o que se pretende explorar é a ideia de uma possível fundamentação moral kantiana no liberalismo político de Rawls, de modo que a concepção inicial de um construtivismo moral permaneceria como um pressuposto incontornável ao construtivismo político, mesmo quando o autor estadunidense defende uma concepção de justiça autossustentável.

Assumindo essa tese, o construtivismo moral kantiano não estaria apenas endossando o liberalismo político ou "exprimindo apenas uma analogia" de modelos construtivistas (RAWLS, 2000 p. 48), senão que aquele serviria como fundamento imprescindível para esse. Isso porque, 
defende-se que o construtivismo político, mesmo prescindindo de todas as doutrinas éticas abrangentes, não poderia se sustentar sem assumir os pressupostos morais da razão prática de Kant, a qual Rawls interpreta a partir de uma concepção procedimental, não comprometida com o fundacionismo apriorístico da razão transcendental. À luz dessa vinculação, a moral kantiana não pode ser considerada simplesmente como mais uma doutrina ética abrangente, como Rawls a qualifica. A filosofia prática kantiana deve ser entendida no sentido moral de uma teoria de princípios universais, e não no sentido ético das concepções particulares de bem. Isso se torna evidente no critério de universalidade do imperativo categórico da razão prática pura, o qual tem primazia quando equiparada às máximas subjetivas da razão prática empírica. Com efeito, a razão prática torna-se determinante na construção e na manutenção da justiça como equidade, uma vez que as concepções utilizadas pelo construtivismo político são reconhecidamente de origem kantiana, as quais permanecem como pressupostos fundamentais para os princípios de justiça. É importante salientar que Rawls faz uma leitura procedimental da moralidade kantiana, na qual a razão prática é caracterizada como uma capacidade reflexiva capaz de construir princípios morais universalmente reconhecidos (RAWLS, 2005, p. 165-291). Aqui, a razão prática mantém-se como a faculdade legitimadora da moralidade, porém não mais como uma autoridade a priori e metafísica, mas sim como uma capacidade reflexiva de cidadãos razoáveis e racionais. Nesse sentido, o tão discutido fundamento moral do liberalismo político estaria naquela concepção filosófica que desde o início inspira e embasa o projeto rawlsiano, a saber: o construtivismo moral de Kant.

Rawls até reconhece que "existe semelhança entre os valores do liberalismo político e os valores dos liberalismos abrangentes de Kant [...]", porém afirma que "a justiça como equidade não tem o intuito de cultivar os valores e as virtudes que são próprios dos liberalismos da autonomia e da individualidade, nem de qualquer outra doutrina abrangente" (RAWLS, 2011, p. 236). Como anteriormente analisado, a partir dos escritos de 1980 , o filósofo estadunidense não hesita em afirmar que o seu liberalismo político 
não tem qualquer vinculação com a concepção moral kantiana (RAWLS, 2011, p. 117-120). No entanto, a questão que deve ser feita é a seguinte: o liberalismo político se sustenta de modo independente, sem pressupor qualquer elemento relacionado à moralidade kantiana? Se não, então parece haver uma fundamentação necessária deste para com aquele, a qual não pode ser compreendida simplesmente como uma subscrição de uma concepção filosófico-moral aos princípios de justiça do liberalismo político.

O primeiro indício que aponta na direção de uma necessária vinculação, entre a concepção política rawlsiana e a moralidade kantiana, encontra-se na origem estrutural do projeto de uma teoria da justiça como equidade. Como evidenciado textualmente, Rawls reconhece na razão prática kantiana a origem do método construtivista na teoria moral (RAWLS, 1997, p. 275283). Isso permite que a ideia de uma teoria da justiça como equidade surja a partir de uma interpretação ressignificativa dos elementos fundamentais da moralidade kantiana. Aliás, Rawls reconhece que o seu objetivo é reinterpretar a razão prática de Kant a partir de outro ponto de vista, aplicando-a a uma concepção social e política de justiça, mediante uma concepção de razão prática procedimental (RAWLS, 2005, p. 275). É claro que este projeto inicial é radicalmente modificado, passando por um processo de politização que termina por afirmar uma concepção política autossustentável, de modo que se rechaça toda e qualquer vinculação ética ou moral, inclusive kantiana. Contudo, o que Rawls não percebe é que alguns elementos da moralidade kantiana, os quais estão implicitamente presentes desde a origem de seu projeto, continuam fundamentando o liberalismo político, a despeito de sua pretensão de autossustentabilidade. Para explorar essa ideia, deve-se ter presente que Rawls faz uma leitura bastante original da moralidade kantiana, interpretando a razão prática como uma faculdade reflexiva capaz de construir princípios morais. A razão prática kantiana, portanto, deixa de ser uma autoridade em si, a qual tem legitimidade transcendental pelo simples factum (KANT, 2011, p. 51-53) de existir. No construtivismo moral, ela torna-se uma faculdade normativa e procedimental, pela qual os cidadãos 
reais podem avaliar, revisar e construir os juízos morais ponderados que fundamentam a estrutura básica da sociedade em que vivem.

Nesse sentido, inicialmente, pode-se considerar que a liberdade transcendental (KANT, 2001, p. 474-494) kantiana, entendida como incondicionada com relação a determinações empíricas, bem como a autonomia moral que se expressa mediante a lei moral (KANT, 2011, p. 54-56), são fundamentos imprescindiveis (ressignificados) para o construtivismo político. $\mathrm{O}$ desprendimento exigido pela autonomia política dos cidadãos, os quais devem ter a capacidade de escolher, revisar e alterar as suas concepções de bem, requer a pressuposição da liberdade moral kantiana. Rawls a considera como uma concepção estritamente política, mas no fundo há como pressuposto a liberdade kantiana. Ora, na medida em que o sujeito moral não se encontra determinado pelo contexto ético-empírico, então ele pode agir de modo incondicionado, escolhendo, revisando e mudando as suas próprias concepções de bem. Do mesmo modo que a liberdade moral evita o completo mecanicismo natural, pelo qual tudo seria determinado, a ressignificação dessa concepção de liberdade possibilita aos sujeitos rawlsianos desprenderem-se de seus contextos particulares, construindo assim princípios políticos racionais e razoáveis.

Nesse contexto, o liberalismo político abandona o fundacionismo metafísico da liberdade transcendental, mas mantém-se dependente da concepção moral de liberdade, entendida segundo o procedimentalismo da razão prática. É, pois, através da liberdade moral que os cidadãos se encontram em condições de construir, por meio da reflexão prática, os princípios políticos da justiça como equidade. Esse mesmo pressuposto os permite avaliar, revisar e edificar as suas próprias concepções de justiça e de bem. Sem assumir como pressuposto essa concepção moral de liberdade, Rawls não poderia desenvolver uma proposta política construtivista, pois essa se fundamenta em um procedimentalismo que exige uma capacidade reflexiva de cidadãos razoáveis, racionais e livres. Isso significa que Rawls está assumindo como pressuposto fundamental ao construtivismo político a capacidade de autodeterminação moral kantiana, na medida em que a 
capacidade reflexiva dos cidadãos (envolvidos na construção de princípios políticos razoáveis) só se torna possível excluindo o determinismo natural e pressupondo a liberdade moral. De outro modo, os cidadãos não teriam a capacidade crítico-reflexiva para avaliar, revisar e construir juízos ponderados sobre os princípios políticos que fundamentam a estrutura básica da sociedade em que vivem. Como em Kant, aqui a liberdade torna-se o pressuposto basilar da razão prática, agora entendida como uma faculdade reflexiva capaz de justificar princípios políticos.

Ademais, a autonomia política defendida pelo liberalismo, bem como o próprio argumento que sustenta a escolha do primeiro princípio de justiça (RAWLS, 1997, p. 64), encontra-se dependente da autonomia moral kantiana. Isso porque a autonomia racional, que modela a autonomia plena dos cidadãos de uma sociedade liberal (RAWLS, 2011, p. 85-97), só terá efetividade se estes cidadãos possuírem autonomia moral, como representada em Kant (KANT, 2011, p. 69). Nessa interpretação, o construtivismo político estaria pressupondo a tese fundamental da autonomia moral kantiana, a saber: o desprendimento de toda e qualquer condição heterônoma, i.e., externa à razão prática, bem como a capacidade racional de autodeterminação da vontade. No liberalismo político, contudo, a autonomia moral torna-se uma capacidade reflexiva (da razão prática) capaz de construir princípios políticos, mediante um procedimento normativo desenvolvido pelos próprios cidadãos razoáveis e racionais. Para tanto, a liberdade moral, a qual permite a autodeterminação pela razão prática, torna-se um pressuposto basilar para a concepção política de autonomia plena.

Nesse sentido, sem pressupor sujeitos moralmente autônomos, como representados no construtivismo moral kantiano, a justiça como equidade até pode ser formalmente apresentada como um procedimento puramente político, mas ela não teria efetividade alguma quando aplicada à estrutura básica de uma sociedade. Isso porque, nesse caso, os cidadãos estariam naturalmente determinados pelo contexto social, de modo que não teriam as condições necessárias para desenvolver a reflexão prática que efetiva os princípios políticos construídos na posição original. Assim, a autonomia 
política estaria necessariamente vinculada à autonomia moral kantiana, pois a base que assegura a escolha dos princípios que constituem a autonomia pública dos cidadãos não é puramente política, senão que profundamente vinculada à posição do filósofo moderno. Segundo Rawls, a autonomia racional (artificial) das partes na posição original não está condicionada por nenhuma doutrina filosófica, de modo que o argumento pretende apresentar princípios essencialmente políticos, independentes de qualquer visão abrangente. A autonomia plena também seria política, pois ela considera os cidadãos a partir de sua identidade pública, orientados pelos princípios escolhidos na situação inicial. Com efeito, se a autonomia das partes na posição original pressupõe uma fundamentação moral kantiana, do mesmo modo a autonomia plena dos cidadãos estaria dependente da correspondente noção kantiana. Isso seria imprescindível para se atingir o equilíbrio reflexivo amplo (wide reflective equilibrium) (RAWLS, 1997, p. 23) entre a cultura política democrática e o modelo normativo construído na situação inicial.

Segundo a concepção política do filósofo estadunidense, a autonomia plena dos cidadãos possibilita um processo deliberativo e constitutivo de juízos morais bem ponderados, os quais são condições necessárias para um equilíbrio entre os princípios construídos pelas partes na posição original e os juízos dos cidadãos racionais e razoáveis em um contexto plural. Isso é fundamental para calibrar, por assim dizer, os princípios construídos na situação inicial com a cultura política de uma sociedade democrática. $O$ que Rawls não evidencia, contudo, é que esse equilíbrio reflexivo amplo exige (inevitavelmente) a pressuposição de uma concepção moral constitutiva dos sujeitos políticos, a saber: a moralidade kantiana. Nesse caso, uma das condições fundamentais para se atingir o equilíbrio reflexivo é pressupor a autonomia moral kantiana como constitutiva da autonomia política dos cidadãos reais, uma vez que essa é modelada pela concepção prática daquela, como uma condição imprescindível na construção normativa dos princípios. A autonomia moral kantiana é uma condição implícita à autonomia política, a qual assegura as condições necessárias para a efetivação de um equilíbrio reflexivo. No fundo, subentendido à 
concepção de autonomia política há um pressuposto moral, o qual assume as ideias de liberdade e autonomia kantianas. A identidade política dos cidadãos, bem como a concepção de liberdade a ela relacionada, só possui efetividade pressupondo a autonomia moral kantiana. Isso porque os três aspectos segundo os quais os cidadãos são considerados como pessoas livres exigem, para que eles de fato se realizem, os pressupostos morais da concepção de autonomia racional do filósofo de Königsberg.

Nesse caso, sem pressupor a liberdade e a autonomia moral kantiana, entendida como a capacidade de autodeterminação pela própria razão prática, os cidadãos políticos não têm efetivas condições para: 1) possuírem a capacidade moral de ter e desenvolver uma concepção de bem, assim como de rever, alterar e ressignificar por motivos racionais e razoáveis esta concepção; 2) considerarem-se como fontes autoautenticativas de demandas válidas; e 3) possuírem a capacidade de assumir a responsabilidade por seus próprios fins, aceitando e promovendo concepções razoáveis e justas. Estas são as condições mediante as quais um cidadão desenvolve efetivamente a sua liberdade política, como estabelecido por Rawls (2011, p. 34-41). Ora, para que estas condições se tornem efetivas, contudo, é imprescindível pressupor e assumir como fundamento a concepção de autonomia kantiana, pois é necessário considerar os cidadãos políticos como pessoas autônomas, como sujeitos capazes de autodeterminação da vontade pela própria razão prática. Caso contrário, como assevera Kant, a vontade humana seria determinada por condições empíricas, pelo que até mesmo a ideia de liberdade política não passaria de uma mera ilusão. Muito embora Rawls rechace qualquer pressuposto moral, parece evidente que a sua concepção de autonomia política se encontra implicitamente fundamentada na autonomia da razão prática de Kant. No procedimentalismo rawlsiano, esse pressuposto vincula-se ao construtivismo da razão prática, não mais como uma autoridade metafísica e transcendental, mas sim como uma capacidade reflexiva de justificar princípios políticos. É, portanto, por este motivo que o equilíbrio reflexivo amplo exige que os cidadãos assumam concepções morais bem ponderadas que implicitamente pressupõem a autonomia kantiana, sem as 
quais não se poderia atingir um equilíbrio entre os princípios construídos na posição original e a cultura política de uma sociedade democrática.

Nessa interpretação, o liberalismo político é encarado como um modelo coerentista, no qual os princípios hipoteticamente construídos na posição original são efetivados pela reflexão prática dos cidadãos razoáveis e racionais na estrutura básica da sociedade. Nesse caso, as partes na posição original (autonomia racional) servem como referências normativas para que os cidadãos reais, mediante as capacidades morais da autonomia plena, possam avaliar, questionar e efetivar os princípios políticos na sociedade em que vivem (RAWLS, 2011, p. 92-97). Na parte não hipotética da teoria da justiça, os cidadãos precisam desenvolver as capacidades morais da autonomia plena para que os princípios de justiça sejam efetivados e aplicados à estrutura social. Se isso não ocorrer, a teoria perde a sua efetividade prática e torna-se uma conjectura artificial e abstrata, apenas. Aqui está a importância do equilíbrio reflexivo, bem como do construtivismo moral kantiano, pois assim a autonomia plena dos cidadãos é desenvolvida e progressivamente vai constituindo juízos morais ponderados. Esse é, aliás, o processo pelo qual se estabelece o equilíbrio reflexivo, no qual a conjetura ideal da teoria é articulada com a estrutura social.

Mesmo assumindo como referência normativa os princípios construídos na posição original, o equilíbrio reflexivo amplo não é algo estático, mas sim um processo contínuo e progressivo, de modo que a reflexão moral dos cidadãos vai construindo juízos ponderados. À medida que o equilíbrio reflexivo vai se desenvolvendo, os juízos morais se tornam gradativamente mais bem ponderados e razoáveis. Esse é um processo contínuo, conduzido pela razão prática, em que a cada passo um novo horizonte normativo se abre, na medida em que os princípios políticos são progressivamente revisados e aperfeiçoados. Nessa interpretação, o construtivismo moral kantiano constitui a base da autonomia plena que oferece as condições necessárias para os cidadãos desenvolverem juízos ponderados, através do equilíbrio reflexivo. O procedimento construtivista exige autonomia moral e capacidade reflexiva do agente, pressupostos 
fundamentais para o processo de equilíbrio reflexivo amplo. Segundo Rawls, "reflexão plena não significa aqui uma reflexão perfeita no momento final, mas essa progressiva reflexão crítica que deve ser conquistada por uma tradição de pensamento de uma geração à outra, de modo que cada vez mais pareça que, se sustentada por uma reflexão mais plena, a visão moral seria construtivista" (RAWLS, 2005, p. 313). Tem-se, aqui, o ponto de tangência entre o construtivismo moral e os juízos ponderados produzidos pelo equilíbrio reflexivo. Esse processo reflexivo, contínuo e progressivo, torna-se fundamental para que a conjetura ideal seja revisada e efetivada na estrutura social, evitando assim o formalismo (que muitos identificam no pensamento kantiano ${ }^{9}$ ) que Rawls tanto busca superar.

Ora, é precisamente nesse contexto em que o construtivismo moral kantiano se torna imprescindível ao liberalismo político rawlsiano. Isso ocorre pela seguinte razão: a autonomia plena dos cidadãos, a qual é a condição fundamental para a constituição de juízos ponderados, através do equilíbrio reflexivo, encontra-se fundamentada na autonomia moral kantiana. Na interpretação rawlsiana, o construtivismo moral é estruturado por meio de um procedimento da razão prática que permite construir normas de ação para um mundo social ajustado. Nesse processo, a razão prática é considerada uma faculdade normativa que se apresenta como uma capacidade reflexiva. Isso significa que cabe ao cidadão real exercer e desenvolver a capacidade reflexiva da razão prática, de modo a construir por si mesmo a normatividade moral. Esse é um procedimento gradativo e contínuo, mediante o qual a razão prática pode avaliar, revisar e construir princípios morais. À luz desta interpretação procedimental da razão prática, percebe-se que a concepção política de autonomia plena se encontra fundamentada na autonomia

\footnotetext{
9 Nesse sentido, por exemplo, tem-se a vigorosa crítica de Hegel à moral kantiana. Para Hegel, grosso modo, a lei moral não passa de uma fórmula vazia de conteúdo efetivo, pelo que o imperativo categórico seria um procedimento tautológico da razão pura. Para aprofundar o conhecimento da posição hegeliana sobre esse assunto, ver: HEGEL, G. Principios de la filosofia del derecho o derecho natural y ciencias políticas. Tradução: Juan Luis Vermal. Buenos Aires: Sudamericana, 1975.
} 
moral kantiana, entendida como uma capacidade reflexiva de construir (autonomamente) princípios normativos. A normatividade procedimental da razão prática kantiana, portanto, estabelece as condições pressupostas à autonomia política dos cidadãos para que esses, mediante o processo de equilíbrio reflexivo amplo, possam construir juízos ponderados.

Com isso, o procedimentalismo da razão prática kantiana, caracterizado pela autonomia reflexiva do construtivismo moral, dá as condições necessárias para a constituição da autonomia plena dos cidadãos, pela qual se desenvolve o processo de equilíbrio reflexivo amplo que produz juízos ponderados. Há, portanto, um pressuposto moral kantiano, o qual se caracteriza pela capacidade reflexiva da razão prática, que fundamenta a autonomia política dos cidadãos que reconhecem publicamente os princípios políticos que fundamentam a estrutura básica da sociedade em que vivem. Esse pressuposto constitui a identidade moral dos cidadãos, tornando-os autônomos e autores de princípios políticos bem ponderados, mediante o contínuo processo de equilíbrio reflexivo. Em um modelo coerentista, esse pressuposto assume uma função primordial: ele oferece as condições necessárias para que os cidadãos, pela capacidade reflexiva da autonomia plena, possam revisar, aprimorar e efetivar (na cultura política) os princípios conjeturados na posição original. Sem pressupor a autonomia kantiana como constitutiva da identidade moral dos cidadãos, o liberalismo político incorre no formalismo abstrato que tanto desejou superar.

Contudo, rechaçando a pressuposição da autonomia kantiana, Rawls vai afirmar que a concepção de autonomia que fundamenta a sua teoria da justiça é política, a qual será denominada de "autonomia doutrinal" (RAWLS, 2011, p. 107-117). A concepção moral kantiana, por outro lado, será considerada como uma autonomia constitutiva, pois ela adentra a ordem da constituição dos valores e envolve princípios mais abrangentes que se aplicam à vida como um todo. Perante essas diferenças, Rawls conclui que "não há dúvida de que o liberalismo político deve rejeitar a autonomia constitutiva de Kant" (RAWLS, 2011, p. 118), uma vez que se faz necessário uma concepção de autonomia estritamente vinculada a princípios políticos. 
Sem pressupor a autonomia moral kantiana, todavia, os princípios do liberalismo não seriam efetivos, de modo que os cidadãos de uma sociedade bem-ordenada não teriam as condições necessárias para a constituição de sua autonomia plena. Com isso, é necessário que o liberalismo político assuma a concepção de autonomia constitutiva kantiana, pois essa dá as condições morais para que os cidadãos efetivem a autonomia política. É, aliás, exatamente isso que Rawls tenta assegurar ao lançar mão da ideia de concepções bem ponderadas, as quais são exigências morais constitutivas que integram a autonomia plena dos cidadãos. O que, contudo, ele não deixa evidente é que essas concepções bem ponderadas, necessárias para o processo de equilíbrio reflexivo amplo, pressupõem os elementos fundamentais da autonomia kantiana. Aquilo que Rawls denomina de autonomia constitutiva, portanto, torna-se algo fundamental para compreender o que ele qualifica como autonomia doutrinal ou política, pois essa só adquire efetividade mediante os pressupostos morais daquela.

À luz do acordo semântico anteriormente proposto, pode-se dizer que a autonomia kantiana é constitutiva da identidade moral, mas não interfere na identidade ética dos cidadãos. Rawls, no entanto, acredita que a concepção de autonomia proposta por Kant é mais profunda, a qual constitui os valores pessoais da identidade ética. Vale lembrar que o autor estadunidense não faz uma distinção semântica entre os conceitos de ética e moral. Há bons argumentos, contudo, para defender que a concepção de autonomia apresentada por Kant é constitutiva da identidade moral dos cidadãos, porém não os determina no âmbito da identidade ética dos valores pessoais. Deve-se ressaltar que o construtivismo moral exige um exercício reflexivo da razão prática, pelo qual são compostos os juízos morais ponderados. Nesse processo, há uma exigência constitutiva da identidade moral dos cidadãos envolvidos no procedimento construtivista, a qual está relacionada à faculdade normativa da razão prática. Os princípios construídos por esse processo reflexivo são avaliados de acordo com critérios objetivos, universais e publicamente reconhecidos. Nesse procedimento construtivista, é necessário que os cidadãos envolvidos possuam autonomia 
prática, constitutiva da identidade moral, pois se exige uma capacidade reflexiva desenvolvida pela razão prática. A identidade ética, contudo, não é determinada pelo procedimento construtivista da razão prática, de modo que ela pode ser livremente constituída de acordo com as preferências individuais de cada cidadão. No pensamento liberal, aliás, isso explica o pluralismo de concepções éticas existentes em sociedades democráticas.

A autonomia moral kantiana, portanto, é constitutiva da identidade moral, porém não determina a identidade ética dos cidadãos, a qual é livremente escolhida pelas preferências pessoais relativas às concepções de bem. Essa diferença torna-se evidente na comparação entre os imperativos hipotéticos da razão prática empírica e os imperativos categóricos da razão prática pura: os primeiros constituem a identidade ética do sujeito, conforme as preferências subjetivas, interesses pessoais e as diferentes concepções de bem que podem ser livremente escolhidas por cada cidadão (Kant toma como exemplo as diversas concepções de felicidade) (KANT, 2011, p. 36-42); enquanto que os segundos constituem a identidade moral, a qual é definida pelos princípios objetivos e universais da lei moral, pelo que são reconhecidos publicamente e apresentam-se como obrigações incondicionais a todos os cidadãos razoáveis e racionais. Rawls tem razão, portanto, ao afirmar que a concepção kantiana de autonomia é constitutiva. Contudo, ele não percebeu que essa autonomia determina apenas a identidade moral dos cidadãos, mantendo uma postura de respeito e neutralidade frente à diversidade de concepções abrangentes de bem que constituem a identidade ética deles. A autonomia constitutiva de Kant, desse modo, adentra e determina a esfera dos princípios morais, todavia não se estende até a ordem dos valores éticos pessoais. Ao não evidenciar essa diferença, Rawls acreditou ser necessário rechaçar a autonomia moral kantiana, separando-a da autonomia política presente na sua teoria da justiça. Entretanto, isso não deve ser feito, pois a primeira constitui a base moral para a efetivação da segunda, como anteriormente analisado.

Nesse cenário, do mesmo modo que a efetivação da autonomia política pressupõe a concepção de autonomia moral kantiana, a esco- 
Iha do primeiro princípio de justiça fundamenta-se em elementos da moralidade deontológica. Aqui, o que se pretende evidenciar é que o princípio basilar do liberalismo político (Equal Liberty Principle) se encontra dependente da moralidade kantiana. Isso porque ele é escolhido por partes racionais e razoáveis que reconhecem a liberdade individual como algo inegociável, opondo-se assim ao utilitarismo, por exemplo. No fundo, o que assegura a justificação do primeiro princípio de justiça é a tese kantiana de que todo sujeito autônomo deve ser considerado como um fim em si mesmo, e não pode ser tratado com simples meio . $\mathrm{Na}$ interpretação construtivista, o que atribui valor absoluto à dignidade humana não é algo metafísico, aprioristicamente estabelecido, mas sim a capacidade reflexiva da razão prática que faz de todo e qualquer cidadão razoável e racional um fim em si mesmo. Esse pressuposto está implícito na origem filosófica da teoria da justiça como equidade, a qual parte de uma interpretação construtivista do projeto kantiano. Por mais que Rawls ressalte a ideia de autossustentabilidade da concepção política de justiça, não há como desprendê-la dos elementos fundamentais do deontologismo kantiano, pois esses estão implicitamente sustentando o princípio que reconhece a liberdade humana como um valor absoluto. Na moralidade kantiana, a capacidade de autodeterminação racional faz do homem um ser possuidor de dignidade, cuja autonomia o torna um fim em si mesmo, com valor absoluto. Com efeito, a contraposição ao argumento utilitarista, que defende a maximização do bem-estar da maioria em detrimento da liberdade de alguns, é um argumento que se fundamenta na moralidade deontológica, pois pressupõe o valor moral inviolável da liberdade humana, muito embora a entenda segundo uma concepção procedimental, desvinculada de elementos transcendentais.

Na medida em que Kant reconhece que todo sujeito racional é autônomo, sendo um fim em si mesmo, o qual não pode se tornar um simples meio, então a postura utilitarista é posta em xeque, visto que a efetivação do bem-estar da maioria requer a utilização de algumas pessoas como meios. A concepção utilitarista não reconhece o igual valor das liberdades 
fundamentais, nem o valor inegociável da dignidade humana, justificada pela capacidade reflexiva da razão prática. No mais, a escolha do primeiro princípio na posição original, bem como o reconhecimento público do direito fundamental à igualdade de liberdades básicas, exige uma fundamentação vinculada à razão prática kantiana, pois é a autonomia moral que torna o ser humano capaz de reconhecer a liberdade como um direito inviolável. O reconhecimento da capacidade humana de autodeterminação pela própria razão prática, como uma faculdade reflexiva capaz de construir a normatividade moral mediante um procedimento, possibilita a justificação e a aceitação pública do princípio basilar do liberalismo político. Graças à capacidade humana de autodeterminação moral, pela capacidade reflexiva da razão prática, a liberdade torna-se um princípio fundamental. O valor inegociável da liberdade e da dignidade humana, justificadas pela autonomia moral kantiana, a qual é ressignificada mediante uma concepção procedimental (desprovida de elementos metafísicos e transcendentais), torna-se um elemento moral fundamental para a estruturação da concepção política de justiça, muito embora Rawls não o reconheça e até mesmo negue qualquer pressuposto kantiano.

Tal pressuposto necessário, mas não evidenciado, faz com que o princípio basilar do liberalismo político seja considerado à luz da concepção de autonomia moral kantiana, entendida como uma capacidade reflexiva de construir, a partir da razão prática, a normatividade moral. No liberalismo político, no entanto, essa ideia ganha um significado procedimental e torna-se uma capacidade normativa da razão prática de construir princípios de justiça, evitando, assim, o fundacionismo metafísico de Kant. Com efeito, a ideia de autossustentabilidade da concepção política de justiça não é válida, pois ela esconde o fundamento moral kantiano que lhe dá sustentabilidade. É, aliás, esse o pressuposto que há na ideia que defende o igual valor moral da cidadania política, independente de condições sociais, de possíveis habilidades e de limitações naturais, ou ainda relativas às concepções éticas de bem que alguém possa professar. Pressupondo a premissa moral kantiana que estabelece um valor igual e absoluto a 
todo e qualquer sujeito autônomo, o qual é capaz de construir a partir de sua própria razão prática a normatividade moral, o liberalismo político rawlsiano afirma que a autonomia política é um princípio igualmente absoluto. A aceitação deste princípio político pressupõe o reconhecimento moral das pessoas como autônomas em sentido kantiano, como cidadãos capazes de construir os princípios políticos que fundamentam a estrutura básica social. Assim como em Kant, o liberalismo político considera todas as pessoas como fins em si mesmas, como cidadãos autônomos que têm a capacidade de autodeterminar as suas escolhas, e que por isso mesmo não podem ser tratados como simples meios. Essa é, portanto, a premissa kantiana que sustenta o argumento político rawlsiano contra 0 utilitarismo ou mesmo contra o perfeccionismo social.

Em síntese, o construtivismo rawlsiano, mesmo apresentando-se como político, parece pressupor traços morais kantianos. Entre eles, o valor inviolável da autonomia, aos moldes da razão prática de Kant, figura como um princípio moral fundamental para o liberalismo político, embora Rawls o interprete segundo o procedimentalismo do imperativo categórico (RAWLS, 2005, p. 192-198), pelo qual a razão prática constrói reflexivamente a normatividade moral. A despeito da pretensão expressa em Political Liberalism, a proposta política de Rawls não consegue se desvincular da filosofia moral kantiana, uma vez que a efetividade da concepção política de justiça depende e está inevitavelmente condicionada às suas origens kantianas, ressignificada pelo procedimentalismo construtivista. Contudo, se for admitido que há um pressuposto moral kantiano ao liberalismo político, como aqui é defendido, então coloca-se em xeque a concepção rawlsiana de autossustentabilidade do âmbito político. Essa independência dos princípios políticos é estabelecida para se levar a cabo um consenso sobreposto sobre valores públicos, os quais devem ser reconhecidos e endossados pelas diversas concepções de bem existentes em uma sociedade democrática e plural. Ora, a pergunta que se impõe, deste modo, é a seguinte: ao assumir um pressuposto moral kantiano, o liberalismo político não estaria comprometendo a viabilidade do consenso sobreposto? A resposta rawlsiana é sim, 
e por isso mesmo ele nega qualquer vinculação entre o construtivismo moral kantiano e o construtivismo político da justiça como equidade. Todavia, não seria possível aceitar a fundamentação moral kantiana e manter em pé a possibilidade de um consenso sobreposto? Rawls rechaça essa possibilidade porque considera a posição kantiana como uma doutrina ética abrangente, como tantas outras existentes em uma sociedade marcada pelo pluralismo razoável. Nesse caso, de fato, não é possível pressupô-la ao liberalismo político e manter em pé a possibilidade de um consenso sobreposto. Não por acaso, o filósofo assevera que o construtivismo moral kantiano pode até subscrever o liberalismo político, porém sem qualquer vinculação necessária entre um e outro. ${ }^{10}$

Nesse sentido, a posição defendida por Rawls considera a filosofia prática kantiana como mais uma das muitas concepções éticas de bem, sobre as quais é impossível se chegar a um acordo político. Como supracitado, o filósofo estadunidense não faz uma distinção rigorosa entre concepções éticas e morais. Aliás, a posição kantiana ora é tratada como uma doutrina moral abrangente, ora como uma concepção ética. Considerando o acordo semântico proposto por Forst, no entanto, é necessário distinguir as concepções éticas de bem dos valores morais, assim como das normas jurídicas e do âmbito político. Nesse caso, a filosofia prática kantiana deve ser entendida como uma concepção moral, pois ela parte de fundamentos objetivos e justifica-se universalmente. Ela não pode ser considerada, portanto, como mais uma das muitas concepções éticas de bem, uma vez que essas não atendem aos critérios de justificação universal e objetivo, mas se pautam em valores privados e constituídos subjetivamente. É necessário reconhecer, portanto, que a doutrina moral kantiana é constitutiva da identidade moral, pois exige a

\footnotetext{
10 Segundo Rawls, "não há dúvida de que o liberalismo político deve rejeitar a autonomia constitutiva de Kant; no entanto, seu construtivismo moral pode subscrever o construtivismo político, até onde vai este último. E o construtivismo político aceita, com toda a certeza, a visão de Kant de que os princípios da razão prática originam-se, se insistirmos em dizer que se originam em algum lugar, em nossa consciência moral informada pela razão prática" (RAWLS, 2011, p. 118).
} 
assimilação de capacidades reflexivas da razão prática. Esses valores são universalmente reconhecidos e aceitos por todos, já que sem eles não há sociedade razoável, nem respeito mútuo entre as pessoas.

Neste ponto, deve-se ressaltar que o construtivismo moral kantiano determina a identidade moral dos cidadãos, pois exige uma postura reflexiva orientada pelo procedimentalismo da razão prática. Isso não significa, todavia, uma determinação da identidade ética dos cidadãos, a qual é subjetivamente constituída pelas escolhas individuais. A filosofia prática kantiana, com efeito, mantém-se neutra com relação às diversas concepções de bem do âmbito ético, respeitando todas aquelas que não contradizem os princípios universais da moralidade. A razão prática pura não determina as máximas subjetivas da razão prática empírica, assim como o respeito à lei moral não impede a busca pela felicidade, mesmo que essa esteja na satisfação de inclinações sensíveis. O que há, portanto, é uma primazia da razão prática pura, enquanto uma faculdade reflexiva capaz de construir princípios morais universalmente válidos, os quais delimitam (mas não eliminam) as concepções razoáveis de bem. Aqui está a base teórica para o estabelecimento da prioridade do justo sobre o bem (RAWLS, 2011, p. 205-207), do mesmo modo que se assegura a viabilidade de um consenso sobreposto acerca de uma concepção objetiva, universal e publicamente reconhecida de justiça.

Ora, é sobre os valores privados das concepções éticas de bem que não há acordo político possível, pelo que se torna impossível um consenso sobreposto a partir do âmbito ético. Com efeito, para manter-se em pé a possibilidade de um consenso sobreposto é necessário estabelecer a independência do âmbito político com relação às concepções éticas de bem, já que sobre elas não há acordo possível. Todavia, torna-se possível aceitar uma fundamentação moral para o âmbito político, sem comprometer a ideia de consenso sobreposto, desde que esse pressuposto atenda aos critérios de objetividade e publicidade dos princípios políticos. A razão prática de Kant atende esses critérios, justamente porque é a partir da universalidade da lei moral kantiana que se extraem as premissas para o construtivismo político 
da justiça como equidade. Assim, a moralidade kantiana pode fundamentar os princípios políticos do liberalismo, sem alterar a sua objetividade e publicidade, pois a validade universal da lei moral atende aos critérios de reciprocidade exigidos no acordo político. O reconhecimento intersubjetivo de princípios políticos razoáveis, bem como de valores sociais fundamentais como igualdade, liberdade e respeito, exige a aceitação de pressupostos constitutivos da identidade moral das pessoas que convivem em sociedade. Esse acordo moral sobre valores universais é imprescindível, pois, de outro modo, os princípios políticos não teriam efetividade. Pode-se assumir, portanto, uma fundamentação moral kantiana para o liberalismo político, sem comprometer a viabilidade do consenso sobreposto. O que não se pode aceitar é um pressuposto ético, pois sobre esse não haveria acordo possível.

\section{Considerações finais}

O projeto filosófico rawlsiano segue uma trajetória teórica marcada por profundas revisões e reformulações aprimorativas, as quais o conduzem a mudanças significativas em aspectos fundamentais de sua teoria. Uma das consequências mais marcantes deste work in progress, certamente, encontra-se na ideia de autossustentabilidade da concepção política de justiça, integralmente exposta na obra de 1993. Political Liberalism rompe, portanto, com a posição apresentada pelo autor em A Theory of Justice (1971), de modo a rechaçar qualquer pressuposto vinculado a doutrinas morais abrangentes. Desde então, os debates relativos a possíveis pressupostos implícitos ao liberalismo político são recorrentes, sobretudo no que diz respeito a doutrinas éticas ou concepções morais que dariam sustentação à concepção política de justiça defendida por Rawls. Autores comunitaristas, por exemplo," articulam vigorosas objeções à ideia de independência do

\footnotetext{
1 Cf. SANDEL, Michael. Liberalism and the Limits of Justice. 2. ed. Cambridge: Cambridge University Press, 1998. MACINTYRE, Alasdair. After Virtue. Notre Dame: University of Notre Dame Press, 1981. TAYLOR, Charles. As Fontes do Self: a construção da identidade moderna. São Paulo: Edições Loyola, 2013.
} 
âmbito político, ressaltando a exigência de se evidenciar as concepções de bem que estariam por detrás do liberalismo político. Nesse enredo, mesmo não corroborando essas críticas comunitaristas, buscou-se mostrar que há pressupostos morais que sustentam a concepção política de justiça rawlsiana.

Nesse sentido, a contribuição do presente trabalho está em acenar para a existência de pressupostos morais kantianos ao liberalismo político, porém sem seguir o viés crítico que o relaciona a concepções éticas de bem. Por esse motivo, fez-se necessário delimitar o significado e os diferentes usos relativos aos conceitos de "ético", "jurídico", "político" e "moral", pois essas distinções não são evidentes no texto rawlsiano. Com isso, foi possível distinguir a posição kantiana de concepções éticas de bem, de modo a ressaltar que a proposta consiste em relacionar os princípios políticos a pressupostos morais, mas não a éticos. Daí, pois, a razão pela qual tal pressuposição não comprometeria a possibilidade de se levar a cabo um consenso sobreposto acerca de uma concepção política de justiça, nem a ideia de prioridade do justo sobre o bem. Em sociedades democráticas marcadas pelo pluralismo de concepções éticas de bem, esse acordo acerca de uma concepção política de justiça torna-se imprescindível. Somente assim é possível estabelecer princípios políticos de justiça fundamentados em valores morais, os quais, mesmo não estando vinculados a concepções éticas de bem, são endossados por elas.

\section{Referências}

DWORKIN, Ronald. Levando os direitos a sério. São Paulo: Martins Fontes, 2002. ESTLUND, David. The insularity of the reasonable: why political liberalism should admit the truth. Ethics, [S. I.], v. 108, n. 2, p. 252-275, 1998. https:// doi.org/10.1086/233804

FORST, Rainer. Kontext der Gerechtigkeit: Politische Philosophie jenseits von Liberalismus und Komunnitarismus. Frankfurt: Suhrkamp, 1994.

FORST, Rainer. Contextos da justiça. Tradução Denilson Luís Werle. São Paulo: Boitempo, 2010. 
FREEMAN, Samuel (org.). The Cambridge Companion to Rawls. New York: Cambridge University Press, 2003. https://doi.org/10.1017/CCOL0521651670

FREEMAN, Samuel. Rawls: Routledge Philosophers. Londres: Routledge, 2007. https://doi.org/10.4324/9780203086605

HAMPTON, Jean. Political philosophy. Boulder: Westview Press, 1996.

HEGEL, G. Principios de la filosofia del derecho o derecho natural y ciencias políticas. Tradução Juan Luis Vermal. Buenos Aires: Sudamericana, 1975.

KANT, Immanuel. Crítica da Razão Pura. 5. ed. Tradução Manuela Pinto dos Santos e Alexandre Fradique Morujão. Lisboa: Editora Fundação Calouste Gulbenkian, 2001.

KANT, Immanuel. Crítica da Razão Prática. 3. ed. Tradução Valério Rohden. São Paulo: Martins Fontes, 2011.

KANT, Immanuel. Fundamentação da Metafísica dos Costumes. Tradução Paulo Quintela. Lisboa: Edições 70, 2007.

KANT, Immanuel. Grundlegung zur Metaphysik der Sitten. Erlagen: Fischer, 1984. KERSTING, Wolfng.John Rawls zur Einführung. 2. ed. Hamburg: Junius Verlag, 2004. KERSTING, Wolfng. Spannungsvolle Rationalitätsbegriffe in der politischen Philosophie von John Rawls. In: APEL, K. O.; KETTNER, M. (org.). Die eine Vernunft und die vielen Rationalitäten. Frankfurt am Main: Suhrkamp, 1996. p. 227-265. LARMORE, Charles. The Autonomy of Morality. Cambridge: Cambridge, 2008. https://doi.org/10.1017/CBO9780511816611

MAHONEY, Jon. Public reason and the moral foundation of political liberalism. In: BROOKS, T.; FREYENHAGEN, F. (ed.). The legacy of John Rawls. New York: Continuum Books, 2007. p. 85-106.

O'NEIL, Onora. Constructions of reason: explorations of Kant's practical philosophy. Cambridge University Press, 1989.

O'NEIL, Onora. Constructivism in Rawls and Kant. In: FREEMAN, S. (org.). The Cambridge Companion to Rawls. Cambridge: Cambridge University Press, 2003. p. 347-367. https://doi.org/10.1017/ccol0521651670.010

PATON, H. The Categorical Imperative: A study in Kant's Moral Philosophy. London: Hutchinson's University Library, 1947.

RAWLS, John. A Theory Justice. Cambridge, Mass.: Harvard University Press, 1971. 
RAWLS, John. História da filosofia moral. Tradução Ana Aguiar Cotrim. São Paulo: Martins Fontes, 2005.

RAWLS, John. Justiça e Democracia. Tradução Irene A. Paternot. São Paulo: Martins Fontes, 2000.

RAWLS, John. Kantian Constructivism in Moral Theory. In: FREEMAN, S. (org.). Collected Papers. Cambridge (Massachusetts): Harvard University Press, 1999. p. 303-358.

RAWLS, John. Lectures on the History of Moral Philosophy. 2. ed. Cambridge (Massachusetts): Harvard University Press, 2003.

RAWLS, John. O liberalismo político. Tradução Álvaro de Vita. São Paulo: Martins Fontes, 2011.

RAWLS, John. Political Liberalism. New York: Columbia University Press, 1993. Paperback edition, 1996.

RAWLS, John. Uma teoria da justiça. Tradução A. Pisetta e L. M. R. Esteves. São Paulo: Martins Fontes, 1997.

WEBER, Thadeu. Fundamentação moral do liberalismo político de Rawls. Ethic@. Florianópolis, Santa Catarina, Brasil, v. 15, n. 3, p. 398-417, dez. 2016. https://doi.org/10.5007/1677-2954.2016v15n3p398

WENAR, Leif. Political liberalism: an internal critique. Ethics, v. 106, p. 32-62, 1995. https://doi.org/10.1086/293777

\section{Endereço postal}

\section{Douglas João Orben}

Faculdade Palotina de Santa Maria

R. Padre Alziro Rogia, 115

Patronato, Santa Maria - RS, 97020-590 